\title{
RNA interference-mediated gene silencing in murine T cells: in vitro and in vivo validation of proinflammatory target genes Tatjana C Gust ${ }^{1}$, Luisa Neubrandt ${ }^{1}$, Claudia Merz ${ }^{2}$, Khusru Asadullah², Ulrich Zügel ${ }^{1}$ and Arne von Bonin*1
}

\author{
Address: ${ }^{1}$ Common Mechanism Research, Bayer Schering Pharma AG, Muellerstrasse 178, 13342, Berlin, Germany and ${ }^{2}$ Target Discovery, Global \\ Drug Discovery, Bayer Schering Pharma AG, Muellerstrasse 178, 13342, Berlin, Germany \\ Email: Tatjana C Gust - tatjana.gust@bayerhealthcare.com; Luisa Neubrandt - luisa.neubrandt@bayerhealthcare.com; \\ Claudia Merz - claudia.merz@bayerhealthcare.com; Khusru Asadullah - khusru.asadullah@bayerhealthcare.com; \\ Ulrich Zügel - ulrich.zuegel@bayerhealthcare.com; Arne von Bonin* - arnevon.bonin@bayerhealthcare.com \\ * Corresponding author
}

Published: 6 August 2008

Cell Communication and Signaling 2008, 6:3 doi:10.1/86/1478-81।X-6-3

This article is available from: http://www.biosignaling.com/content/6/1/3

(c) 2008 Gust et al; licensee BioMed Central Ltd.

This is an Open Access article distributed under the terms of the Creative Commons Attribution License (http://creativecommons.org/licenses/by/2.0), which permits unrestricted use, distribution, and reproduction in any medium, provided the original work is properly cited.
Accepted: 6 August 2008
Received: 27 May 2008

\begin{abstract}
Background: T cells play a central role in many inflammatory diseases, hence the identification and validation of $T$ cell-specific target genes will increase the understanding of $T$ cell function in pathologic inflammatory situations. RNA interference (RNAi), with its ability to induce specific gene silencing in mammalian cells, represents a powerful technology to investigate and validate the function of pharmaceutical target genes in vitro and in vivo. The aim of the present study was to systematically explore RNAi-mediated gene-silencing of known $T$ cell-specific model signaling molecules in primary murine $T$ cells in vitro and in vivo.

Results: We demonstrate that siRNA delivery and subsequent silencing of $T$ cell specific genes is substantially increased, if murine $T$ cells were activated prior siRNA transfection. Silencing of ZAP70, p56Lck as well as PLC- $\gamma$ I protein expression resulted in impaired function of T cells in vitro. Furthermore, delayed type hypersensitivity (DTH) was ameliorated in vivo after adoptive transfer of ZAP70-silenced T cells.

Coclusion: The combination of RNAi-mediated gene silencing and adoptive transfer of genesilenced $T$ cells, thus, may allow the identification and analysis of $T$ cell-specific targets for therapeutic intervention. Additionally, this model system may represent an alternative to conventional time consuming and cost intensive gene targeting approaches.
\end{abstract}

\section{Background}

RNAi is a naturally occurring mechanism of gene regulation conserved in plants and mammalian cells. The mechanism of RNAi was identified and characterized almost a decade ago in the nematode worm Caenorhabditis elegans [1]. It relies on double-stranded (ds), small interfering RNAs (siRNAs) of 21-23 nucleotides that induce sequence-specific gene silencing in mammalian cells [2].
siRNAs derive from long dsRNAs that trigger the RNAi machinery and are cleaved by the RNaseIII-like enzyme Dicer [3]. siRNAs are incorporated into the RNA-induced silencing complex (RISC) that comprises helicase, exonuclease, and homology-searching domains. The siRNA duplex is unwound and the antisense strand mediates mRNA recognition and thereby, mRNA degradation and subsequent gene silencing. Over the last few years, RNAi 
has evolved as a new technology for specific gene knockdown that allows analysis of gene function in vitro and in vivo and the identification of new molecular targets associated with disease, such as cancer and inflammation [47].

$\mathrm{T}$ cells constitute one of the major components of the adaptive, cellular immune system. They play a pivotal role in the onset, balance and maintenance of immune responses as well as autoimmunity. Adaptive immune responses are initiated by interactions of $\mathrm{T}$ cells with antigen-presenting cells (APC), such as dendritic cells, in the secondary lymphoid organs. T cells become activated and develop into effector cells by a series of activation signals consisting of i) antigen presentation by APC via peptidemajor histocompatibility (MHC) complexes that stimulate the T-cell receptor (TCR, [6]), ii) costimulation by B7 family members that bind to CD28 expressed on T cells [7]. Upon engagement of the TCR, a signaling cascade inside the cell is initiated that leads to activation of the $\mathrm{T}$ cell. The Src family of protein tyrosine kinases Fyn and Lck become activated and phosphorylate the cytoplasmic domains of the $\mathrm{CD} 3$ complex which then interact with the zeta-chain-associated protein kinase 70 (ZAP70). ZAP70 is subsequently phosphorylated by p56Lck and Fyn and stimulates downstream signaling events leading to the recruitment and activation of a number of other signaling proteins, such as phospholipase C gamma (PLC- $\gamma ;[8,9]$.

Before the discovery of RNAi, studies of gene function mainly relied on knockout strains, protein overexpression and protein-protein interaction assays. However, the knockout of genes results in a complete lack of gene ontology and can cause embryonic lethality or induce compensatory mechanisms. Protein overexpression may result in non physiological conditions and thereby lead to incorrect interpretation of gene function. Whereas successful RNAi in human T cells has been documented in literature $[10,11]$, primary murine T cells are difficult to transfect and therefore published data desribing an efficient protein knockdown in mouse $\mathrm{T}$ cells are scarce $[12,13]$.

Here, we report a systematic analysis of RNAi-mediated gene modulation for model target genes in primary murine T cells. We investigated the transfection of siRNA molecules into primary murine T cells in vitro and tested such gene-silenced $\mathrm{T}$ cells in an adoptive cell transfer model of DTH based on Ovalbumin (OVA) TCR-transgenic T cells in vivo. Efficient siRNA delivery and subsequent silencing of ZAP70 protein expression strongly depended on T cell activation. ZAP70-silenced T cells displayed impaired function in vitro as well as in vivo by inducing less DTH than cells transfected with control siRNA. The combination of RNAi in murine T cells and the in vivo analysis of gene-silenced $\mathrm{T}$ cells by adoptive transfer may represent a powerful technique to identify and validate novel signaling pathways and inflammationrelevant target genes in T cell biology.

\section{Methods \\ Mice}

Eight-12 weeks old BALB/c mice were purchased from Charles River Laboratories (Sulzfeld, Germany). Age- and sex-matched DO11.10 mice were kindly provided by C. Doebis (Deutsches Rheumaforschungszentrum, Berlin, Germany). T cells of DO11.10 mice express a transgenic TCR recognizing $\mathrm{OVA}_{323-339}$ peptide bound to I-A ${ }^{\mathrm{d}}[14]$. All animal experiments were performed in accordance with institutional, state, and federal guidelines.

\section{Generation of $T$ cells and ThI cells}

$\mathrm{T}$ cells of BALB/c mice were isolated from splenocytes by immunomagnetic bead purification using the mouse Pan T cell isolation kit according to the manufacturer's instructions (Miltenyi Biotec, Bergisch Gladbach, Germany).

Th1 cells were generated in vitro from lymph node cells and splenocytes of DO11.10 mice. Single cell suspensions of splenocytes and lymph node cells were prepared and erythrocytes lysed with $0.83 \% \mathrm{NH}_{4} \mathrm{Cl}$. Cell concentration was adjusted to $2 \times 10^{6}$ cells $/ \mathrm{ml}$ and lymph node cells were co-cultured with splenocytes at a ratio of 1:2.5 in 6well plates. Cells were grown in VLE-RPMI 1640 medium with stable glutamine (Biochrom, Berlin, Germany) containing $10 \%$ heat-inactivated FCS, $50 \mu \mathrm{M} \beta$-mercaptoethanol (Sigma, Germany), $100 \mathrm{U} / \mathrm{ml}$ penicillin and $100 \mu \mathrm{g} /$ $\mathrm{ml}$ streptomycin sulfate (Invitrogen, Karlsruhe, Germany). Recombinant mouse IFN $\gamma(20 \mathrm{ng} / \mathrm{ml})$, IL-12 (10 $\mathrm{ng} / \mathrm{ml}$, both R\&D systems) and $\mathrm{OVA}_{323-339}$ peptide $(1 \mu \mathrm{g} /$ $\mathrm{ml}$; synthesized at the Department of Biochemistry, Humboldt University, Berlin, Germany) were added to the culture. After 3 days of culture, cells were used for transfection with siRNA and cultured for another $72 \mathrm{~h}$ to allow for knockdown of mRNA and protein expression. $72 \mathrm{~h}$ after transfection, cells were used for adoptive cell transfer.

\section{Restimulation}

Transfected BALB/c T cells or Th1 cells were restimulated either with plate-bound anti-mouse $\mathrm{CD} 3 \varepsilon$ antibody (10 $\mu \mathrm{g} / \mathrm{ml}$; clone 145-2C11, BD Biosciences, Heidelberg, Germany) or with PMA ( $25 \mathrm{ng} / \mathrm{ml}$, Sigma, Germany) and ionomycin $(1 \mu \mathrm{g} / \mathrm{ml}$, Sigma, Germany). Supernatant was removed $24 \mathrm{~h}$ later and analyzed for the secretion of the cytokines interleukin-2 (IL-2) and interferon gamma (IFN- $\gamma$ ) by ELISA (eBioscience, San Diego, USA). For ${ }^{3} \mathrm{H}-$ thymidine incorporation cells were pulsed with $0.5 \mu \mathrm{Ci}$ ${ }^{3} \mathrm{H}$-thymidine/well (Amersham Biosciences, GE Healthcare, Munich, Germany) at day 3 of culture. Cells were harvested 6 hours later and ${ }^{3} \mathrm{H}$-thymidine incorporation 
was measured in a Microbeta Counter (Wallac, Turku, Finland).

\section{Transfection}

After 3 days, $2 \times 10^{7}$ Th1 cells of DO11.10 mice and/or anti-mouse CD3-stimulated T cells or lymph node cells of $\mathrm{BALB} / \mathrm{c}$ mice were transfected by nucleofection using the mouse $\mathrm{T}$ cell Nucleofector kit and the corresponding transfection programme for murine $\mathrm{T}$ cells from AMAXA (Cologne, Germany). Cells were transfected with functional, non-targeting control siRNA (siControl, non-targeting siRNA pool, Dharmacon, Lafayette, USA), a siRNA pool consisting of four siRNAs specific for ZAP710, Lck or PLC- $\gamma 1$ (siGENOME SMART pool, Dharmacon, Lafayette, USA) or three individual ZAP70-specific Stealth ${ }^{\mathrm{Tm}}$ siRNAs (Invitrogen, Karlsruhe, Germany). The targeted sequence of the ZAP70-specific stealth ${ }^{\mathrm{TM}}$ siRNAs are as follows: stealth $^{\mathrm{TM}} \quad$ siRNA \#1: 5'UCUCGUACACACUUGUGUCCAUGGG3', stealth $^{\text {тм }}$ siRNA \#2: 5'AAUUAGUCCAUCGCGCUUCAGCUUC3', stealth $^{\mathrm{TM}} \quad$ siRNA \#3: UUGUCUGUCGAUGACGCUAAGGCUG3'. Briefly, cells were transfected with different amounts of siRNA and cultured in complete medium and 12-well plates for up to 72 $\mathrm{h}$ for subsequent analysis or adoptive cell transfer. Transfection efficiency for GFP plasmid DNA yielded 30\% of GFP-positive cells under the applied conditions The transfection effiency with siRNAs was $70-80 \%$ determined with fluorescently-labeled siRNAs. Viability of murine $\mathrm{T}$ cells transfected by nucleofection was $40-50 \%$.

\section{RNA isolation, CDNA synthesis and RT-PCR}

For the detection of mRNA knockdown by RT-PCR $1 \times 10^{6}$ transfected cells were lysed with Nucleic Acid Purification Lysis solution (Applied Biosystems, Darmstadt, Germany) and mRNA was isolated using a ABI Prism ${ }^{\mathrm{TM}} 6100$ Nucleic Acid PrepStation (Applied Biosystems, Darmstadt, Germany). cDNA synthesis of RNA samples was performed with TaqMan ${ }^{\circledast}$ Reverse Transcription Reagents (Applied Biosystems, Darmstadt, Germany). Samples were incubated for $10 \mathrm{~min}$ at room temperature, $30 \mathrm{~min}$ at $48^{\circ} \mathrm{C}$ and $5 \mathrm{~min}$ at $95^{\circ} \mathrm{C}$. Subsequent RT-PCR was performed in triplicates for each gene using TaqMan ${ }^{\circledast}$ Gene Expression Assays specific for Lck (Mm 00802897_m1), PLC- $\gamma 1$ (Mm 01247275_m1), ZAP70 (Mm00494255_m1) and $\beta$-actin (Mm00607939_s1, all Applied Biosystems, Darmstadt, Germany) and following the manufacturer's protocol The reactions were run on the GeneAmp ${ }^{\circledast}$ PCR System 9700 thermal cycler with the following amplification program: $50^{\circ} \mathrm{C}$ for $2 \mathrm{~min}, 95^{\circ} \mathrm{C}$ for $10 \mathrm{~min}$, followed by 40 cycles of $95^{\circ} \mathrm{C}$ for $15 \mathrm{~s}, 60^{\circ} \mathrm{C}$ for $1 \mathrm{~min}$. Data was analyzed using Sequence Detection Systems Software v2.2.1 (Applied Biosystems, Darmstadt, Germany) and the gene of interest was normalized to the corresponding $\beta$-actin results.

\section{Protein isolation and Western blot analysis}

Protein expression of siRNA-transfected cells was analyzed by Western blot analysis. At least $2 \times 10^{6}$ cells were lysed in lysis buffer (50 mM Tris- $\mathrm{HCl}$ pH 7.5, $150 \mathrm{mM}$ $\mathrm{NaCl}, 2 \mathrm{mM}$ EGTA, $1 \mathrm{mM}$ NAF, 1\% Triton X-100, $1 \mathrm{mM}$ sodium orthovanadate + complete protease inhibitor cocktail tablets (Roche, Mannheim, Germany)). $5 \mu \mathrm{g}$ of protein lysate determined by BCA Protein Assay Kit (Pierce, Bonn, Germany) and were separated on $10 \%$ SDS-PAGE gels and blotted onto PVDF membranes (Biorad, Munich, Germany). Proteins were identified using anti-Lck, (clone 3A5, Millipore, Schwalbach, Germany), anti-PLC- $\gamma 1$ (clone D-7-3, Millipore, Schwalbach, Germany), anti-ZAP70 (clone 4H386, USBiological, Massachusetts, USA) and anti- $\beta$-actin (clone AC-74, SigmaAldrich, Schnelldorf, Germany) antibodies. As secondary antibody HRP-conjugated IgG sheep anti-mouse polyclonal serum (GE Healthcare, Munich, Germany) was used and developed with ECL reagents (ECL kit, Amersham Biosciences, GE Healthcare, UK).

\section{Th I-mediated DTH model}

The Th1-mediated DTH model was performed as described before [15] with minor modifications. Briefly, a total of $1 \times 10^{6}$ transfected Th1 cells generated from DO11.10 mice were injected intravenously into the tail veins of naïve BALB/c mice. Adoptively transferred cells were either mock transfected, transfected with a control siRNA pool or with ZAP70-specific siRNA. $24 \mathrm{~h}$ after adoptive cell transfer, the DTH response was induced by subcutaneous injection of $250 \mathrm{ng} \mathrm{OVA}_{323-339}$ peptide together with incomplete Freund's adjuvant (IFA) into the right footpad. As control, the left footpad was injected s.c. with PBS/IFA. $24 \mathrm{~h}$ after antigen injection, footpad thickness was determined as parameter for the inflammatory response using a specialized micrometer (Bayer Schering Pharma AG, Berlin). Experimental research on animals followed internationally recognized guidelines and was approved by government authorities in Berlin.

\section{Statistics}

Data are presented as mean \pm SD. Significance was determined by Mann-Whitney U test. Differences were considered statistically significant with $\mathrm{p} \leq 0.05$ and highly significant with $\mathrm{p} \leq 0.01$.

\section{Results \\ Stimulation of murine T cells is required to reduce ZAP70 protein expression via RNAi}

To investigate whether $T$ cell activation improves transfection efficiency and thereby RNAi-mediated knockdown of ZAP70 in murine T cells, $\mathrm{T}$ cells from Balb/c mice were stimulated with anti-mouse CD $3 \varepsilon$-specific antibody or left untreated for $24 \mathrm{~h}$. Stimulated and unstimulated cells were transfected with control siRNA or ZAP70-specific 
siRNA pool by nucleofection and ZAP70 silencing was determined in the cell lysates by RT-PCR and Western blot analysis (Fig. 1). In the unstimulated T cells, mRNA expression of ZAP70 was reduced $48 \mathrm{~h}$ and $72 \mathrm{~h}$ after nucleofection. Reduced quantities of ZAP70-specific mRNA, however, did not translate into a knockdown of ZAP70 protein (Fig. 1B, note the stronger $\beta$-actin signal in the unstimulated ZAP70 probe at 72 hours). In contrast to the unstimulated cells, mRNA and protein silencing of ZAP70 was already detectable in the stimulated cell fraction $24 \mathrm{~h}$ after transfection and this was maintained until 72 hours post transfection. The observed correlation of $\mathrm{T}$ cell activation and efficient protein knockdown in the case of ZAP70 gene expression, was extended by RNAi studies employing p56Lck and PLC- $\gamma 1$ as model targets. Here

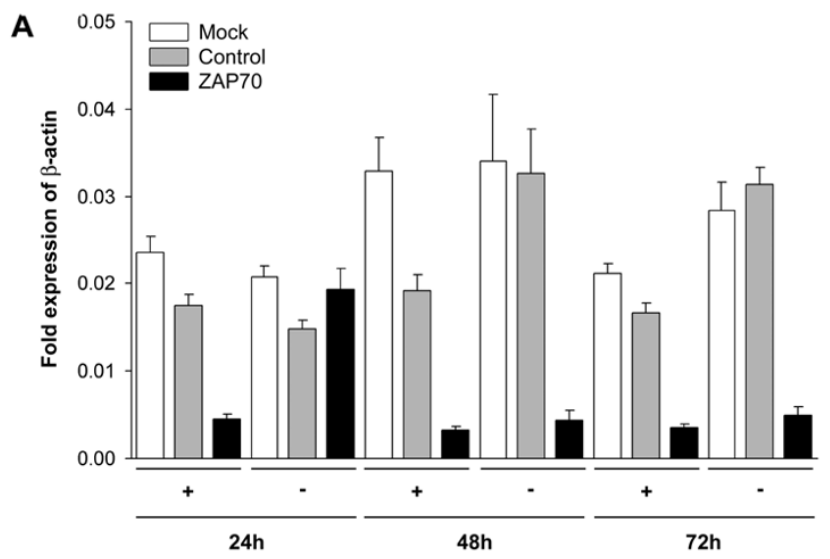

B

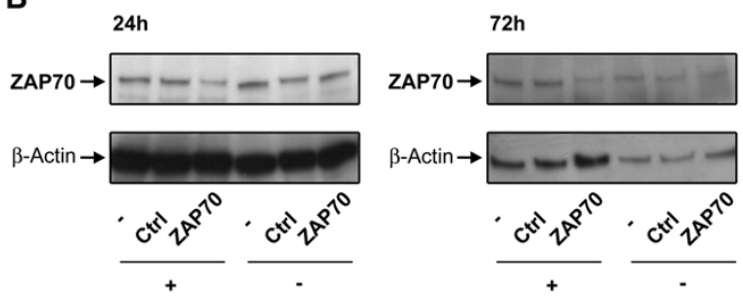

Figure I

Stimulation is required to silence ZAP70 expression in T cells. Murine T cells were stimulated ("+", anti-mouse CD3 $\varepsilon$ ) or left untreated ("-"). 24 h later, cells were transfected with $0.9 \mu \mathrm{M}$ ZAP70-specific siRNA pool by nucleofection. Cell lysates were prepared 24,48 and $72 \mathrm{~h}$ after transfection and ZAP70 expression was analyzed by RT-PCR (A) and Western blot analysis (B). As control, cells were mock ("-", no siRNA added) transfected () or cells were transfected with a control siRNA pool (Ctrl). (A) RT-PCR of ZAP70 mRNA expression determined as fold expression of the house keeping gene $\beta$-actin. (B) Western blot analysis of ZAP70 was detected by ZAP70-specific antibody. $\beta$-actin was used as loading control. Shown are the mean values of triplicates of a representative experiments of four independent experiments. again, stimulation of murine $\mathrm{T}$ cells was a prerequisite for successful RNAi-mediated gene silencing (Fig. 2 and data not shown). Hence, $\mathrm{T}$ cell receptor-triggered activation seems to be an important prerequisite for efficient RNAimediated modulation of protein expression in murine $\mathrm{T}$ cells.

\section{Modified siRNAs allow efficient silencing of ZAP70}

Next, we tested the efficiency of unmodified and chemically modified ZAP70-specific siRNAs to induce ZAP70 RNA and protein knockdown. Stimulated $T$ cells were transfected with the previously used ZAP70-specific siRNA pool or three individual stealth ${ }^{\mathrm{TM}}$ siRNAs. ZAP70

A

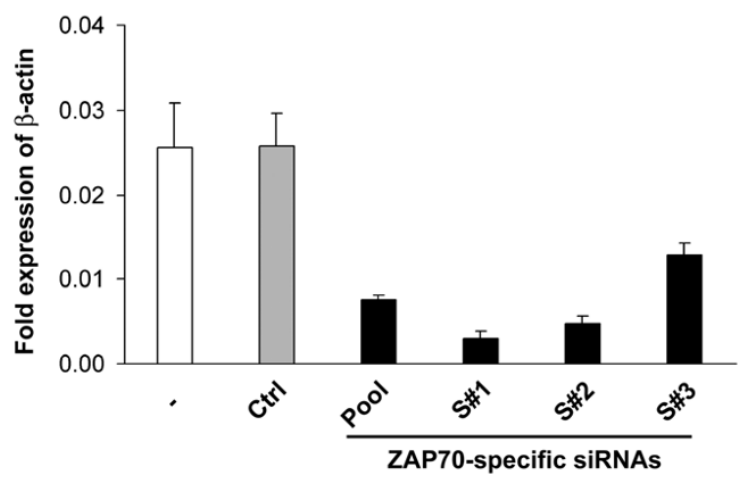

B

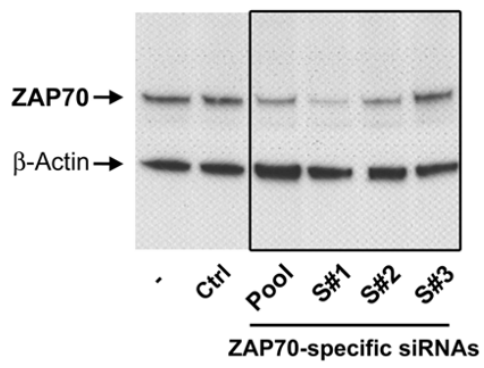

Figure 2

Modified siRNAs allow efficient silencing of ZAP70 silencing $m R N A$ and protein. Stimulated murine $T$ cells were transfected with $0.9 \mu \mathrm{M}$ ZAP70-specific siRNA pool (Pool) or three different stealth ${ }^{\mathrm{TM}}$ siRNAs (S\#I, S\#2, and S\#3) by using nucleofection. Cell lysates were prepared 24 and $48 \mathrm{~h}$ after transfection and ZAP70 expression was analyzed by RT-PCR (A) and Western blot analysis (B). As control cells were mock transfected ("-", no siRNA added), or transfected with a control siRNA pool (Ctrl). (A) RT-PCR of ZAP70 mRNA expression in transfected T cells determined $24 \mathrm{~h}$ after nucleofection as fold expression of the house keeping gene $\beta$-actin. (B) Western blot analysis of transfected T cells $48 \mathrm{~h}$ after nucleofection with siRNAs indicated in $(A)$. Protein knockdown of ZAP70 was detected by ZAP70-specific antibody. $\beta$-actin was used as loading control. Shown are the mean values of triplicates of a representative experiments of two independent experiments. 
knockdown was analyzed in the cell lysates by RT-PCR and Western blot 24 and $48 \mathrm{~h}$ after nucleofection (Fig. 2). As in previous experiments, the siRNA pool efficiently silenced ZAP70 mRNA and protein expression. Stealth ${ }^{\text {тм }}$ siRNA \# 1 was potent in reducing ZAP70 mRNA and protein expression, whereas stealth ${ }^{\mathrm{TM}}$ siRNA \# 2 and 3 were less potent as indicated by the RT-PCR and Western blot results. These results demonstrate that our initial findings employing pools of siRNAs can be reproduced with mono-specific, chemically modified siRNAs.

\section{RNAi is applicable for signaling proteins involved in T cell activation}

After successful silencing of ZAP70 mRNA and protein expression in murine T cells, we tested RNAi to modulate protein expression of additional, again well-characterized, key molecules involved in T cell signaling. To this end we selected p56Lck and PLC- $\gamma 1$ for further analysis. Mouse T cells were activated and subsequently transfected with a siRNA control pool or siRNA pools specific for p56Lck, PLC- $\gamma$, or ZAP70. Transfection with specific siRNAs strongly reduced ZAP70 mRNA expression in activated T cells to background levels, while transfection with both p56Lck and PLC- $\gamma$ siRNA pools reduced mRNA expression by $75 \%$ (Fig. 3). The results of Western blot analysis correlated well with the RT-PCR results: ZAP70 protein expression under the experimental conditions was substantially reduced, whereas p56Lck and PLC- $\gamma$ proteins were still present in the transfected $\mathrm{T}$ cells although at reduced levels as detected in Western blot.

\section{RNAi of $T$ cell-specific signaling molecules alters murine $T$ cell function in vitro}

The effect of RNAi-induced p56Lck, PLC- $\gamma$ and ZAP70 protein knockdown on $\mathrm{T}$ cell function was further investigated in vitro quantifying the proliferation and cytokine release of siRNA-treated T cells. Previously activated T cells, transfected with p56Lck, PLC- $\gamma 1$ or ZAP70 siRNAs, were incubated for 3 days and then restimulated by TCRspecific (anti-CD3 antibody) or TCR-independent (PMA and ionomycin) treatment. IL- 2 and IFN- $\gamma$ secretion and proliferation were determined by ELISA and ${ }^{3} \mathrm{H}$-thymidine incorporation, respectively (Table 1). Both, cytokine production and cell proliferation, were clearly reduced in T cells transfected with p56Lck-, PLC- $\gamma 1$ or ZAP70-specific siRNAs, when the T cells were activated via the TCR. RNAi of the tested genes specifically interfered with TCRdependent pathways and does not exert its function via non-specific, e.g. toxic transfection-related mechanisms, since all transfected T cells equally well responded to PMA and ionomycin stimulation. Hence, using the described experimental setup, i.e. activation of T cells and nucleofection, RNAi allows specific loss-of-function studies in primary murine $\mathrm{T}$ cells in vitro.
A

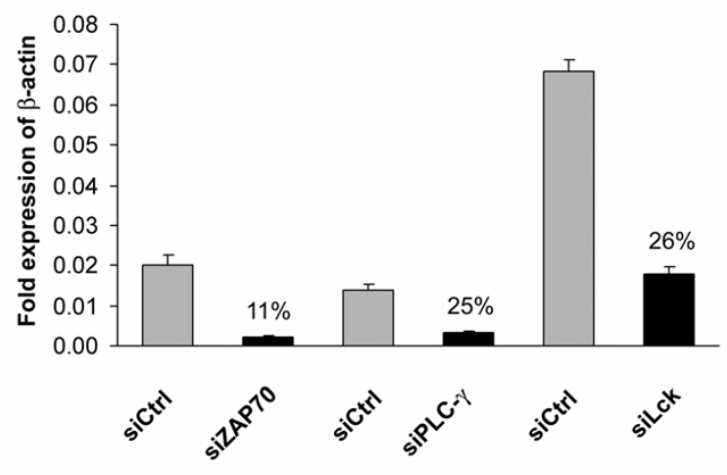

B
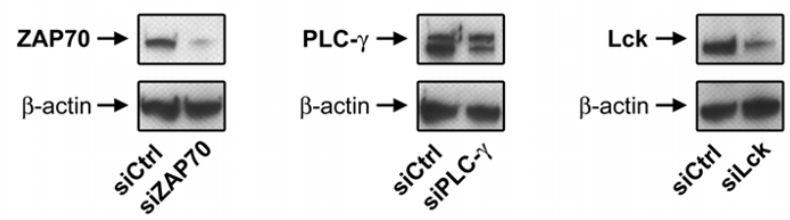

Figure 3

RNAi is applicable for signaling proteins involved in T cell activation. Stimulated murine $T$ cells were transfected with $0.9 \mu$ M ZAP70-, PLC- $\gamma$ - or Lck-specific siRNA pool by using nucleofection. Cell lysates were prepared 24 and $48 \mathrm{~h}$ after transfection and mRNA and protein expression were analyzed by RT-PCR (A) and Western blot analysis (B). As control, cells were transfected with a control siRNA pool (Ctrl). (A) RT-PCR results of transfected T cells determined $24 \mathrm{~h}$ after nucleofection with Control ("siCtrl"), ZAP70 ("siZAP70"), PLC- $\gamma$ ("siPLC- $\gamma$ I") and Lck ("siLck") specific siRNAs. (B) Western blot analysis of transfected T cells $48 \mathrm{~h}$ after nucleofection. Protein knockdown of ZAP70, PLC- $\gamma$ and Lck was detected by specific antibodies. $\beta$-actin was used as loading control. Shown are the mean values of triplicates of a representative experiments of two independent experiments.

\section{RNAi of ZAP70 alters murine $T$ cell function in vivo}

In order to analyze murine $T$ cells in vivo, we used $\mathrm{T}$ cells from DO11.10 TCR-transgenic T cells, which allows the induction and tracing of an immune response with defined antigen specificity in vitro and in vivo. Since in our hands the RNAi-mediated protein knockdown was most efficient for the T cell-specific ZAP70 as model gene, activated DO11.10 T cells transfected with ZAP70 specific siRNAs were first functionally analyzed by in vitro restimulation. Transfection of DO11.10 T cells with ZAP70-specific siRNAs, as shown before for non TCRtransgenic murine $\mathrm{T}$ cells (Table 1 ), resulted in substantially reduced IL-2 secretion after CD3-mediated stimulation (Fig. 4A). Subsequently, ZAP70-silenced T cells were further investigated in an adoptive cell transfer model of 
Table I: Proliferation, IL-2 and IFN- $\gamma$ production of stimulated and siRNA-transfected BALB/c T cells.

\begin{tabular}{|c|c|c|c|c|}
\hline & siRNA & IL-2 [pg/ml] & IFN- $\gamma[\mathbf{p g} / \mathrm{ml}]$ & Proliferation [CPM] \\
\hline \multicolumn{5}{|l|}{$\alpha$ CD3 } \\
\hline & Ctrl & $1417 \pm 144$ & $965 \pm 105$ & $4106 \pm 433$ \\
\hline & Lck & $443 \pm 93$ & $357 \pm 50$ & $540 \pm 220$ \\
\hline & PLC- $\gamma$ & $195 \pm 28$ & $146 \pm 26$ & $236 \pm 19$ \\
\hline & ZAP70 & $400 \pm 60$ & $467 \pm 149$ & $568 \pm 69$ \\
\hline \multicolumn{5}{|l|}{ PMA + lonomycin } \\
\hline & Ctrl & $1980 \pm 2$ & $5067 \pm 346$ & $19919 \pm 787$ \\
\hline & Lck & $2167 \pm 0$ & $4158 \pm 135$ & $16640 \pm 954$ \\
\hline & PLC- $\gamma$ & $1676 \pm 28$ & $2939 \pm 88$ & $11285 \pm 658$ \\
\hline & ZAP70 & $1991 \pm 2$ & $4603 \pm 277$ & $15987 \pm 1906$ \\
\hline
\end{tabular}

T cells were transfected with $0.9 \mu \mathrm{M}$ Lck-, PLC- $\gamma$ - and ZAP70-specific siRNA pool, ZAP70-specific stealth ${ }^{\text {TM }}$ siRNA I and with control siRNA pool (Ctrl). $72 \mathrm{~h}$ after nucleofection, functionality of transfected cells was tested by restimulation with anti-mouse CD3 antibody or PMA and ionomycin in vitro. IL-2 and IFN- $\gamma$ production was determined in the supernatant $24 \mathrm{~h}$ after restimulation by ELISA. Means of duplicate values are shown. Proliferation of $\mathrm{T}$ cells was detected by ${ }^{3} \mathrm{H}$-thymidine incorporation $96 \mathrm{~h}$ after restimulation. Values of ${ }^{3} \mathrm{H}$-thymidine incorporation are shown in means of triplicates.

DTH (Fig. 4B). Adoptive transfer of transfected DO11.10 T cells into Balb/c mice, elicited a significantly $(\mathrm{p} \leq 0.001)$ reduced DTH response in the recipient mice compared to T cells transfected with control siRNA. Our results show that RNAi-mediated modulation of $\mathrm{T}$ cell function can also be exploited in inflammatory model systems in vivo.

\section{Discussion}

The present study describes the application of RNAi technology in primary murine $\mathrm{T}$ cells and for the first time its successful application in an adoptive cell transfer model of DTH in vivo.

In our hands, activation of murine T cells was a prerequisite for successful RNAi-mediated knockdown. This has not been described in detail before (Choi et al., 2006; Chung et al., 2007) and may be specific for the nucleofection transfection technology we employed in combination with our cells of interest - murine T cells. For optimal RNAi-induced protein knockdown several factors like cellular uptake, half-life of the target mRNA (and the protein), and the structure and accessibility of the target mRNA need to be considered [16-18]. Possibly, activation of murine $\mathrm{T}$ cells improves the accessibility of the target mRNA and/or structure as well as transfection efficiency. Using GFP reporter constructs (data not shown), we could demonstrate that in activated and transfected murine $\mathrm{T}$ cells a higher percentage of the T cells was GFP-positive when compared to naïve, unstimulated murine T cells.

Our data demonstrate that knockdown efficiency can differ between the genes of interest and are in line with data describing that sequence, structure, half-life and turnover rate of the target mRNA need to be considered for successful RNAi-based modulation of protein expression $[4,5,19]$. The investigations presented in this study inten- tionally focussed on known model proteins being critical for TCR-mediated signaling events during T cell activation in order to have a clear phenotypic readout, e.g. reduced cytokine secretion, in the silenced cells. We clearly show that an efficient siRNA-mediated knockdown of p56Lck, PLC- $\gamma 1$ and ZAP70 is possible in activated murine T cells with the consequence that the siRNA-treated $\mathrm{T}$ cells exhibited an altered functional phenotype regarding cytokine secretion and proliferation. Having optimized the experimental conditions for siRNA delivery into murine T cells, our results may be extended to other relevant molecules expressed in $\mathrm{T}$ cells in future investigations.

Recently, RNAi technology also facilitated more detailed investigations on the role of kinases in TCR-mediated signaling using in vitro activated $\mathrm{T}$ cells or $\mathrm{T}$ cell lines [20-22]. Here, we describe the impact of a kinase knockdown (ZAP70) in vivo by an adoptive cell transfer model of DTH. This adoptive cell transfer model offers the unique advantage to evaluate the role of target genes in its corresponding in vivo environment of inflammation. Loss-offunction studies by RNAi and adoptive cell transfer may, thus, represent a new method to study direct correlations between gene expression and the function of the respective protein in an inflammatory response. Murine in vivo models rely mainly on transgenic and knockout strains. However, gene targeting in mice can, on one hand, cause embryonic lethality or on the other hand, in the case of transgenic expression, lead to non-physiological protein expression. Although the number of elegant inducible knockout strains is constantly increasing, experiments employing these mouse strains are time consuming and cost-intensive. Here, we show that under defined experimental conditions, i.e. pre-activation of the T cells, RNAi technology represents a powerful tool to validate $\mathrm{T}$ cell specific genes in murine T cells, which can subsequently 

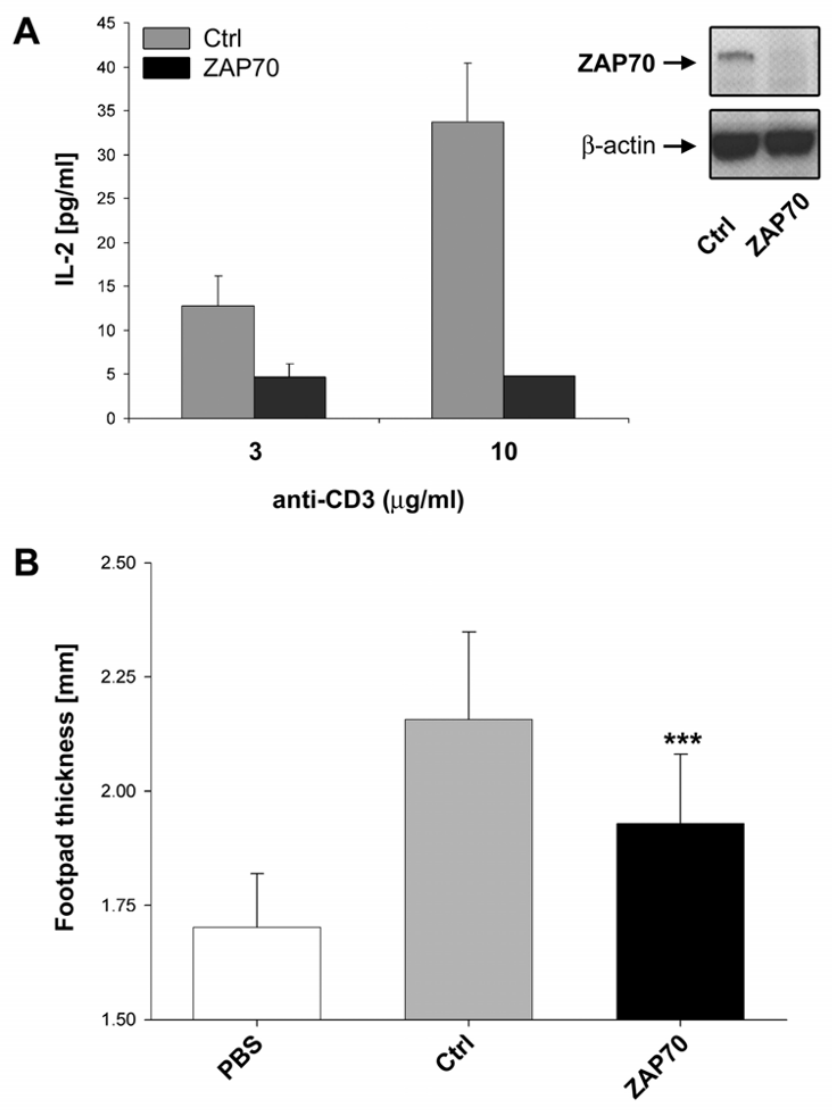

Figure 4

RNAi-mediated knockdown of ZAP70 affects T cell function in vitro and in vivo. DOII.IO T cells were either mock transfected, transfected with a control siRNA pool (Ctrl), or transfected with $0.9 \mu$ M ZAP70-specific stealth ${ }^{\mathrm{TM}}$ siRNA \#I (ZAP70). $72 \mathrm{~h}$ after nucleofection, functionality of transfected cells was tested by restimulation $(\alpha-C D 3)$ in vitro or by adoptive cell transfer into naïve recipient mice in vivo.

(A) I $\times 10^{6} \mathrm{DO} / \mathrm{I} .10 \mathrm{~T}$ cells were restimulated with 3 or 10 $\mu \mathrm{g} / \mathrm{ml}$ anti-mouse CD3 antibody. IL-2 production was determined in the supernatants by ELISA. Means of duplicate values are shown.(B) I $\times 10^{6}$ transfected ThI cells were adoptively transferred via i.v. injection into Balb/c mice. Cells were either mock transfected, transfected with a control siRNA pool or with ZAP70-specific siRNA. $24 \mathrm{~h}$ after adoptive cell transfer, DTH response in the footpad was induced by s.c. injection of OVA peptide/IFA in recipients of cells transfected with control or ZAP70-specific siRNA. As control, recipient mice having obtained mock transfected cells were challenged with PBS/IFA. Footpad thickness was determined $24 \mathrm{~h}$ after antigen exposure. (*** $\mathrm{p} \leq 0.00 \mathrm{I})$. Shown is the mean value of 20 mice in total (per group) analyzed in three independent experiments.

be used in established in vivo animal models to better understand the regulation and contribution of inflammation-relevant genes.

\section{Competing interests}

The authors declare that they have no competing interests.

\section{Authors' contributions}

TCG, LN performed the experiments and were involved in drafting the manuscript (TCG). CM contributed in analysis and interpretation of the data, KA, UZ contributed to conception and design of the data and $A v B$ has been involved in designing the studies and drafting/revising the manuscript.

\section{Acknowledgements}

The authors thank C. Doebis, Deutsches Rheumaforschungszentrum, Berlin, Germany for providing DOI I.I 0 transgenic mice and M. Lehnert and A. Schmidt for excellent technical assistance.

\section{References}

I. Fire A, Xu S, Montgomery MK, Kostas SA, Driver SE, Mello CC: Potent and specific genetic interference by double-stranded RNA in Caenorhabditis elegans. Nature 1998, 391:806-8II.

2. Elbashir SM, Harborth J, Lendeckel W, Yalcin A, Weber K, Tuschl T: Duplexes of 21 -nucleotide RNAs mediate RNA interference in cultured mammalian cells. Nature 200I, 4 I I:494-498.

3. Bernstein E, Caudy AA, Hammond SM, Hannon GJ: Role for a bidentate ribonuclease in the initiation step of RNA interference. Nature 200I, 409:363-366.

4. Berns K, Hijmans EM, Mullenders J, Brummelkamp TR, Velds A, Heimerikx M, Kerkhoven RM, Madiredjo M, Nijkamp W, Weigelt B, et al:: A large-scale RNAi screen in human cells identifies new components of the p53 pathway. Nature 2004, 428:43I-437.

5. Lu PY, Xie FY, Woodle MC: Modulation of angiogenesis with siRNA inhibitors for novel therapeutics. Trends Mol Med 2005, II:I04-II3.

6. Zinkernagel RM, Doherty PC: Immunological surveillance against altered self components by sensitised $T$ lymphocytes in lymphocytic choriomeningitis. Nature 1974, 25 I:547-548.

7. Greenwald RJ, Freeman GJ, Sharpe AH: The B7 family revisited. Annu Rev Immunol 2005, 23:5 I 5-548.

8. van Oers NS, Killeen N, Weiss A: Lck regulates the tyrosine phosphorylation of the $T$ cell receptor subunits and ZAP-70 in murine thymocytes. J Exp Med 1996, 183:1053-1062.

9. Negishi I, Motoyama N, Nakayama K, Nakayama K, Senju S, Hatakeyama S, Zhang Q, Chan AC, Loh DY: Essential role for ZAP-70 in both positive and negative selection of thymocytes. Nature 1995, 376:435-438.

10. McManus MT, Sharp PA: Gene silencing in mammals by small interfering RNAs. Nat Rev Genet 2002, 3:737-747.

II. Mao CP, Hung CF, Wu TC: Immunotherapeutic strategies employing RNA interference technology for the control of cancers. J Biomed Sci 2007, 14:15-29.

12. Choi H, Cho SY, Schwartz RH, Choi K: Dual effects of Sprouty I on TCR signaling depending on the differentiation state of the T cell. I Immunol 2006, I 76:6034-6045.

13. Chung JS, Dougherty I, Cruz PD Jr, Ariizumi K: Syndecan-4 mediates the coinhibitory function of DC-HIL on T cell activation. J Immunol 2007, I79:5778-5784.

14. Murphy KM, Heimberger $A B$, Loh DY: Induction by antigen of intrathymic apoptosis of CD4+CD8+TCRlo thymocytes in vivo. Science 1990, 250:1720-I723.

15. Feuerer M, Eulenburg K, Loddenkemper C, Hamann A, Huehn J: Selflimitation of ThI-mediated inflammation by IFN-gamma. J Immunol 2006, I 76:2857-2863.

16. Kretschmer-Kazemi Far R, Sczakiel G: The activity of siRNA in mammalian cells is related to structural target accessibility: a comparison with antisense oligonucleotides. Nucleic Acids Res 2003, 31 : 4417-4424.

17. Mescalchin A, Detzer A, Wecke M, Overhoff M, Wunsche W, Sczakiel G: Cellular uptake and intracellular release are major obstacles to the therapeutic application of siRNA: novel options by phosphorothioate-stimulated delivery. Expert Opin Biol Ther 2007, 7:1531-1538. 
18. Overhoff M, Alken M, Far RK, Lemaitre M, Lebleu B, Sczakiel G, Robbins I: Local RNA target structure influences siRNA efficacy: a systematic global analysis. J Mol Biol 2005, 348:87 I-88I.

19. Kolfschoten IG, van Leeuwen B, Berns K, Mullenders J, Beijersbergen RL, Bernards R, Voorhoeve PM, Agami R: A genetic screen identifies PITXI as a suppressor of RAS activity and tumorigenicity. Cell 2005, I 2 I:849-858.

20. Vang T, Abrahamsen H, Myklebust S, Enserink J, Prydz H, Mustelin T, Amarzguioui M, Tasken K: Knockdown of C-terminal Src kinase by siRNA-mediated RNA interference augments $T$ cell receptor signaling in mature T cells. Eur J Immunol 2004, 34:2191-2199.

21. Srivastava KK, Batra S, Sassano A, Li Y, Majchrzak B, Kiyokawa H, Altman A, Fish EN, Platanias LC: Engagement of protein kinase Ctheta in interferon signaling in T-cells. J Biol Chem 2004, 279:299। I-29920.

22. Methi T, Ngai J, Mahic M, Amarzguioui M, Vang T, Tasken K: Shortinterfering RNA-mediated Lck knockdown results in augmented downstream T cell responses. J Immunol 2005, 175:7398-7406.

Publish with Biomed Central and every scientist can read your work free of charge

"BioMed Central will be the most significant development for disseminating the results of biomedical research in our lifetime. "

Sir Paul Nurse, Cancer Research UK

Your research papers will be:

- available free of charge to the entire biomedical community

- peer reviewed and published immediately upon acceptance

- cited in PubMed and archived on PubMed Central

- yours - you keep the copyright

Submit your manuscript here:

http://www.biomedcentral.com/info/publishing_adv.asp 